J. Dairy Sci. 99:183-193

http://dx.doi.org/10.3168/jds.2015-9547

(C) American Dairy Science Association ${ }^{\circledR}, 2016$.

\title{
The effect of extrinsic attributes on liking of cottage cheese
}

\author{
E. M. Hubbard, S. M. Jervis, and M. A. Drake ${ }^{1}$ \\ Department of Food, Bioprocessing and Nutrition Sciences, Southeast Dairy Foods Research Center, North Carolina State University, \\ Raleigh 27695
}

\section{ABSTRACT}

Preference mapping studies with cottage cheese have demonstrated that cottage cheese liking is influenced by flavor, texture, curd size, and dressing content. However, extrinsic factors such as package, label claims, and brand name may also influence liking and have not been studied. The objective of this study was to evaluate the role of package attributes and brand on the liking of cottage cheese. A conjoint survey with Kano analysis $(\mathrm{n}=460)$ was conducted to explore the effect of extrinsic attributes (brand, label claim, milkfat content, and price) on liking. Following the survey, 150 consumers evaluated intrinsic attributes of 7 cottage cheeses with and without brand information in a 2-d crossover design. Results were evaluated by 2-way ANOVA and multivariate analyses. Milkfat content and price had the highest influence on liking by conjoint analysis. Cottage cheese with $2 \%$ milkfat and a low price was preferred. Specific label claims such as "excellent source of calcium (>10\%)" were more attractive to consumers than "low sodium" or "extra creamy." Branding influenced overall liking and purchase intent for cottage cheeses to differing degrees. For national brands, acceptance scores were enhanced in the presence of the brand. An all-natural claim was more appealing than organic by conjoint analysis and this result was also confirmed with consumer acceptance testing. Findings from this study can help manufacturers, as well as food marketers, better target their products and brands with attributes that drive consumer choice.

Key words: cottage cheese, extrinsic attributes, consumer liking

\section{INTRODUCTION}

Cottage cheese is a fresh cultured dairy product defined as a "soft uncured cheese prepared by mixing cot-

Received March 7, 2015.

Accepted September 2, 2015.

${ }^{1}$ Corresponding author: maryanne_drake@ncsu.edu tage cheese dry curd with a creaming mixture" (21CFR 133.128; Code of Federal Regulations, 2004). Cottage cheese lost a significant amount of consumer market share in the 1970s and 1980s (Reiter, 1993), and sales have continued to slowly decline in recent years (Dairy Market Trends, 2005; Davis et al., 2010). In the United States, 511 million $\mathrm{kg}$ of cottage cheese were manufactured in 2011, an increase in production compared with 185.4 million $\mathrm{kg}$ produced in 2006 (USDA National Agricultural Statistics Service, 2007). Cottage cheese is primarily consumed by the young $(<25 \mathrm{yr}$ old $)$ and individuals 55 yr old and older (Davis et al., 2010). Companies have altered packaging to make cottage cheese more appealing and convenient, and product flavor and texture have become more consistent due to better quality controls (Makhal et al., 2013), but the product may still be seen by most consumers as a diet food (Tong, 2013). High-quality cottage cheese by dairy judging standards should have a mild, diacetyl flavor with little to no aftertaste, and curds should be uniform in size and shape, with a meaty texture without being too firm or rubbery (Bodyfelt and Potter, 2009). Drake et al. (2009) confirmed that consumers also preferred buttery (diacetyl) flavor as well as salty taste, milkfat flavor and mouth coating, and smoothness of texture in cottage cheese.

Studies of the sensory and consumer perceptions of cottage cheese are limited. Antinone et al. (1994) demonstrated that the flavor compound diacetyl had a positive effect on consumer acceptance of cottage cheese, which was later confirmed in a preference mapping study conducted by Drake et al. (2009). Studies have addressed the effect of a variety of processing and packaging methods on cottage cheese flavor and texture characteristics (Puspitasari et al., 1991; Maniar et al., 1994; Monsoor et al., 2003). A limited number of studies have evaluated consumer preferences for cottage cheese, and none have included the role of extrinsic factors.

Consumer behavior in product choice in a grocery store is a complex process influenced by both sensory (intrinsic) product attributes as well extrinsic attributes (brand, packaging, label claims, and other market influences; Moskowitz et al., 2006; Gelici-Zeko et al., 2012). Consumer testing has shown that if the external 
nonsensory characteristics of a product are accepted, the product is more likely to be accepted and the sensory characteristics of the product will drive liking (Moskowitz et al., 2006; Childs et al., 2008; Bayarri et al., 2011; Torres-Moreno et al., 2012). Brand and other label characteristics can also alter consumer liking of a food product (Jervis et al., 2012b; Paasovaara et al., 2012; Torres-Moreno et al., 2012; Kim et al., 2013). Depending on the type of product, the influence of brand may have more or less of an influence on liking. Priilaid (2006) demonstrated that wine liking was strongly influenced by branding. Kim et al. (2013) showed that consumer acceptance of chocolate milk was influenced by fat and sugar content more than brand. A dark chocolate consumer acceptance and purchase intent study by Torres-Moreno et al. (2012) demonstrated that purchase intent of dark chocolates was largely affected by the brand. Sixty-five percent of consumers indicated that they would purchase premium brand chocolate compared with $40 \%$ for store brand.

Methodologies exist for assessing the importance of extrinsic factors on product liking. Two such methodologies are Kano analysis and conjoint analysis. Kano analysis is a consumer research tool that can be used to define the relationship between customer needs and customer satisfaction (Xu et al., 2008; Kuo et al., 2014). This method is used to identify particular attributes with the potential to produce customer satisfaction/ delight and dissatisfaction/frustration (Xu et al., 2008). This form of analysis is particularly useful and unique because it can identify asymmetric and nonlinear relationships between variables (Chen, 2012). Conjoint analysis is another technique that can be used to assess the importance of extrinsic product features. Conjoint analysis, also referred to as trade-off analysis, allows a quantitative assessment and comparison of multiple attributes across multiple products. It can be used to determine consumer drivers of purchase and relative importance of various product features that typically characterize a product. In addition, conjoint analysis can be key in product development by allowing for hypothetical products to be evaluated compared with products currently on the market (Mahanna et al., 2009). Both Kano analysis and conjoint analysis have been used in a wide range of food applications including sour cream, chocolate milk, produce, and eggs to determine the importance of extrinsic and intrinsic product attributes on acceptance (Mesías et al., 2011; Onozaka and McFadden, 2011; Jervis et al., 2012a; Kim et al., 2013). To our knowledge, no published studies have evaluated the role of extrinsic attributes of cottage cheese. The objective of this study was to evaluate the effects of packaging attributes and brand on consumer liking of cottage cheese.

\section{MATERIALS AND METHODS}

\section{Experimental Overview}

An online survey $(\mathrm{n}=460)$ was performed with cottage cheese consumers to determine the influence of packaging, fat content, brand, and label claim on purchase intent of cottage cheese. The survey had 2 components; an adaptive-choice-based conjoint (ACBC) and a section with Kano satisfaction/dissatisfaction attribute questions. A consumer acceptance test $(\mathrm{n}=$ 150) was subsequently conducted with 7 cottage cheeses evaluated with brand and without brand.

\section{Conjoint Analysis and Kano Analysis}

An online survey was created using SSI Web (Sawtooth Software version 7.0.22, Orem, UT). Five attributes (fat content, pricing, brand, label claim, and package size) were selected based on current commercial products. Levels within each attribute were selected to encompass a comprehensive range of choices that consumers would encounter in a typical purchasing environment (Table 1). The survey was designed as an ACBC analysis model using one build-your-own (BYO) sequence (Orme, 2010). The BYO sequence was followed by 10 screening tasks with 4 product concepts per task, with the possible responses of "a possibility" or "won't work for me" for each product concept (Cunningham et al., 2010; Jervis et al., 2012a; Kim et al., 2013). These questions were followed by 10 choice task tournament segments consisting of 3 concepts per choice task. The $\mathrm{ACBC}$ was chosen as the form of conjoint used in this study because ACBC has been previously reported to yield more accurate individual utility scores because of the adaptation while maintaining choice behavior, and requires fewer respondents (Cunningham et al., 2010; Gensler et al., 2012; Jervis et al., 2012a).

Consumers were asked a series of Kano-related questions to determine how their satisfaction/dissatisfaction was influenced by cottage cheese attributes. Both the satisfaction and dissatisfaction questions in the survey were phrased, "If you have the following choices for cottage cheese, how will you feel?" The answer choices for satisfaction and dissatisfaction question were: like, must have, do not care, can live with it, and dislike (Xu et al., 2008). Kano results are used to gain insight on how product features may influence consumer liking of a product by placing product attributes into categories into 4 categories, including must have, attractive, indifferent, and one-dimensional.

The survey was uploaded to an Internet server, and cottage cheese consumers $(n=460)$ were recruited through e-mail list-serves and internet postings on 
campus and from an online consumer database of 5,500 individuals in the Raleigh, North Carolina, area maintained by the North Carolina State University Sensory Service Center. Qualified consumers were between 18 and $65 \mathrm{yr}$ of age, and consumed cottage cheese at least once per month. Consumers first answered demographic and lifestyle (weight and healthiness of eating habits) questions followed by conjoint questions. Respondents then answered a series of Kano-related questions. Respondents who completed the entire conjoint analysis and Kano survey were entered into a drawing to receive one $\$ 100$ gift card or one of five $\$ 20$ gift cards to a local store.

Table 1. Conjoint attributes and levels evaluated

\begin{tabular}{|c|c|}
\hline Attribute & Levels \\
\hline Brands & $\begin{array}{l}\text { Breakstone } \\
\text { Daisy Brand } \\
\text { Darigold } \\
\text { Dean's } \\
\text { Great Value } \\
\text { Horizon } \\
\text { Lactaid } \\
\text { Organic Valley } \\
\text { Simply Kraft } \\
\text { Store brand: Great Value, Food Lion, } \\
\text { Harris Teeter }\end{array}$ \\
\hline Label claims & $\begin{array}{l}\text { Regular } \\
\text { All natural } \\
\text { Excellent source of calcium } \\
\text { Organic } \\
\text { Digestive benefits (probiotic) } \\
\text { Low sodium } \\
\text { Extra creamy }\end{array}$ \\
\hline Fat content & $\begin{array}{l}\text { Full } 4 \% \text { milkfat } \\
\text { Reduced } 2 \% \text { milkfat } \\
\text { Low/light/lite } 1 \% \text { milkfat } \\
\text { Fat free }\end{array}$ \\
\hline Package size (ounces) & $\begin{array}{l}24 \\
16 \\
4 \text { (snack size) }\end{array}$ \\
\hline Curd size & $\begin{array}{l}\text { Large } \\
\text { Small }\end{array}$ \\
\hline Dressing/curd ratio & $\begin{array}{l}\text { High } \\
\text { Somewhat high } \\
\text { Moderate } \\
\text { Somewhat low } \\
\text { Low }\end{array}$ \\
\hline Price $(\$)$ & $\begin{array}{l}1.50 \\
1.75 \\
2.00 \\
2.25 \\
2.50 \\
2.75 \\
3.00 \\
3.25 \\
3.50 \\
3.75 \\
4.00 \\
4.25\end{array}$ \\
\hline
\end{tabular}

Table 2. Cottage cheeses evaluated in consumer acceptance test

\begin{tabular}{llc}
\hline Treatment & Brand type $^{1}$ & Milkfat $(\%)$ \\
\hline 1 & NB & 2 \\
2 & NB & 2 \\
3 & RB & 2 \\
4 & RB & 1 \\
5 & OB & 2 \\
6 & SB & 2 \\
7 & SB & 1 \\
\hline
\end{tabular}

${ }^{1} \mathrm{NB}=$ national brand, $\mathrm{RB}=$ regional brand, $\mathrm{OB}=$ organic brand, $\mathrm{SB}=$ store brand.

\section{Consumer Acceptance Test}

Seven brands of cottage cheese were selected for consumer acceptance testing. Products included were 2 national brands, 2 regional brands, 1 organic brand, and 2 store brands (Table 2). Low fat ( $2 \%$ milk fat) product was used based on conjoint results, and when it was not available, $1 \%$ milk fat product was used. All products were purchased locally, at a minimum of $2 \mathrm{wk}$ before pull date, and were stored at $4^{\circ} \mathrm{C}$ before testing.

Consumer acceptance testing was performed in compliance with the North Carolina State University (NCSU) Institutional Review Board. Consumers were recruited from an online consumer database of 5,500 individuals in the Raleigh, North Carolina, area maintained by the NCSU Sensory Service Center. A screening survey was created using SSI Web (Sawtooth Software Version 7.12, Sequim, WA). One hundred fifty cottage cheese consumers were recruited and participated in the consumer acceptance test. Targeted consumers were between ages 18 and 65 yr old with an even distribution of each age bracket $(10 \mathrm{yr})$. All panelists consumed cottage cheese at least a few times per month. Testing was conducted on 2 different days with a 3-wk interval between test days to avoid carryover effects in a balanced design (MacFie et al., 1989).

Two evaluation conditions were conducted: a tasting where the brand was identified before tasting (session A), and a tasting where the brand was not known during the evaluation (unbranded, session B). Following the unbranded taste test, consumers evaluated their acceptance of the cottage cheese brands by evaluating the brand images on a computer screen (session B). Each consumer participated in both sessions with $3 \mathrm{wk}$ between tests. Consumers were randomly assigned to either session A or B upon arrival and participated in the subsequent session after the 3 -wk waiting period. Before tasting, each consumer looked at the sample and evaluated the appearance and color. The participants were then instructed to taste the sample and answer questions regarding overall acceptability, flavor, fresh- 
ness, saltiness, texture, and curd size. Each of these questions were evaluated using a 9-point hedonic scale from 1 = dislike extremely to $9=$ like extremely. Five point just-about-right questions were asked regarding saltiness, texture, curd size, dressing-to-curd ratio, and mouthfeel of each product using a 5-point scale on 1 $=$ too little, $3=$ just about right, $5=$ too much, with appropriate anchors for each attribute asked (e.g., not nearly salty enough, much too salty, much too small, much too large, not nearly enough dressing, much too much dressing, not nearly smooth/creamy enough, much too smooth/creamy).

Cottage cheeses were served at $4^{\circ} \mathrm{C}$. Prior to serving, each cottage cheese was screened for off-flavors by 2 highly experienced individuals $(>500 \mathrm{~h}$ experience each in the evaluation of dairy products). Sixty grams of each cottage cheese was served in a $120-\mathrm{mL}$ clear-lidded soufflé cup that was labeled with a 3-digit code. Consumers were instructed to rinse with deionized water and take a bite of unsalted cracker in between each sample and before their first sample. A 3-min rest and palate cleanse was enforced between samples. Compusense Five version 5.2 (Compusense, Guelph, Canada) was used for data collection. All participants were compensated with a $\$ 50$ gift card to a local store after completing their second day of participation.

\section{Statistical Analysis}

Statistical analyses were conducted using XLSTAT (v.2010. 2.02, Paris, France). Utility scores were extracted using hierarchical Bayesian estimation and rescaled using a zero-centered differences method (Orme, 2010). Importance scores were determined by calculating the utility score range of each attribute and dividing by the total utility range multiplied by 100 (Orme, 2010). Utility and importance scores were evaluated by ANOVA using XLSTAT (v. 2010, Addinsoft, Paris, France). Cluster analysis of utility scores was conducted with $\mathrm{K}$ means and discriminant analysis was used for validation. A map of cluster membership and attribute preferences estimated by utility scores was generated using principal component analysis (XLSTAT). Kano index and satisfaction or dissatisfaction coefficients were calculated by preparing a contingency table of participant responses to each satisfaction or dissatisfaction question (Xu et al., 2008).

Demographic and behavior questions were analyzed for frequency of choice. All statistical analyses were carried out at a 95\% significance level. Consumer liking scores were evaluated by ANOVA followed by Fisher's least significant difference test. To study the effect of brand and product, a 2-way ANOVA for brand name and treatment (cottage cheese) was conducted. Internal preference mapping of consumer responses to each product under blind, expected, and informed conditions was conducted using principal component analysis.

\section{RESULTS AND DISCUSSION}

\section{Conjoint Analysis}

Conjoint utility scores are used to interpret differences within an attribute and can only be compared within each respective attribute. Consumer response (n $=460$ ) zero-centered utility scores for the brand attribute showed that the national brand, Breakstone, had the highest utility within consumer responses (Table 3 ). The score for this brand was followed by a regional brand (Daisy Brand). Within the brand attribute, the lowest scores were received by products not found or not readily available in the local North Carolina region at the time of the survey and likely received a reduced score due to lack of brand familiarity. The brand Lactaid may have received reduced score due to low product and brand familiarity or a lack of overall demand for lactose free cottage cheese. Unfamiliar brands in similar studies have produced low utility scores attributed to lack of brand market share (Hoyer and Brown, 1990; Varela et al., 2010; Kim et al., 2013). In terms of label claim for cottage cheese, the level "all natural" had the highest utility score and was at parity with digestive benefits (probiotic) and regular (no claim). Lower utility scores followed for other levels: excellent source of calcium, organic, low sodium, and extra creamy.

Reduced 2\% milkfat received the highest utility score for fat content. Low/light/lite $1 \%$ milkfat, fat-free $0 \%$ milkfat, and full $4 \%$ milkfat levels had lower utility scores, respectively. Results from similar studies suggest that consumers seek a compromise between higher fat and (healthier) lower fat products (RichardsonHarman et al., 2000; Jervis et al., 2012a). For package size, 16 ounces earned the highest utility score followed by 24 - and 4-ounce package sizes. We expected that 16- and 24-ounce packages would be preferred because the majority of commercial grocery store cottage cheese product is offered in these sizes, and the 4-ounce size is a relatively recent introduction. Similar studies regarding sour cream package size suggested that a medium (16 ounces) package size was preferred for functional reasons, but smaller sizes may be selected due to a reduced overall price (Jervis et al., 2012a). Among price levels, the lowest price for a container, $\$ 1.50$, received the highest utility score. Interestingly, utility scores within this category did not exhibit a linear decrease in value as the produce price increased. This is likely 
Table 3. Zero-centered utility values for levels of each segment from the conjoint analysis

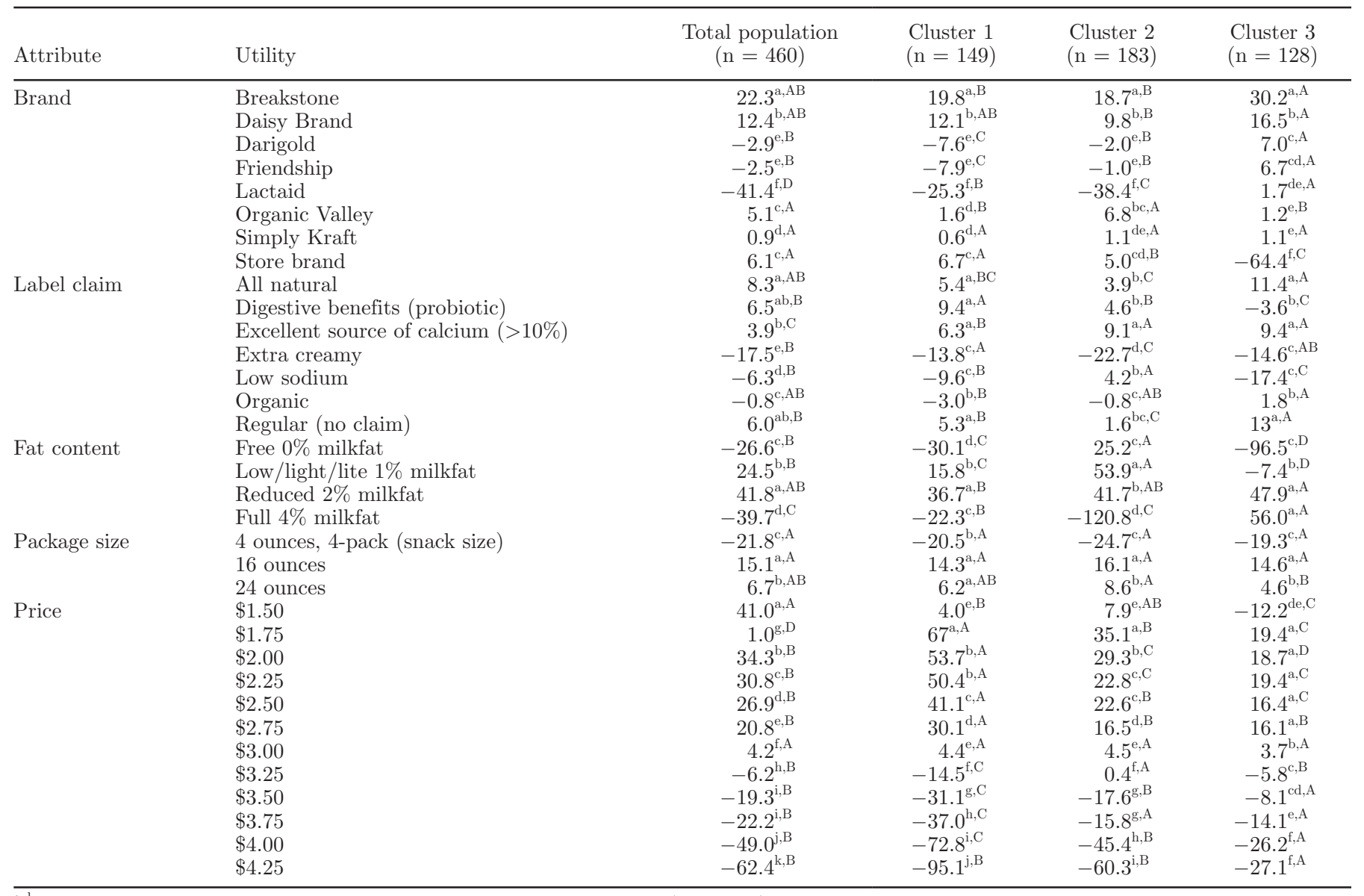

${ }^{\mathrm{a}-\mathrm{k}}$ Lowercase letters within a column within an attribute are different $(P<0.05)$.

${ }^{\mathrm{A}-\mathrm{D}}$ Uppercase letters indicate differences across columns within each specific utility $(P<0.05)$.

due to a negative association between low price and product quality within some of the consumer segments (Andreyeva et al., 2010).

Conjoint analysis was used to determine the value that consumers placed on external attributes of cottage cheese. Conjoint importance scores are used to interpret differences between attributes. A higher score indicates that the attribute is more important to consumers. Fat content had the highest importance score, followed by pricing, brand, label claim, and package size, respectively (Figure 1). Fat content has also been observed to be an important attribute in the acceptance of other food products. It is expected that fat content would be important to product acceptance because previous studies with other dairy products (chocolate milk, sour cream) have also confirmed that fat was a key attribute (Jervis et al., 2012a; Kim et al., 2013). Looking at the utility score distribution for fat content, a reduction in fat had a positive effect on acceptance compared with a full-fat product. A fat-free product was not as attractive as a fat-reduced product. This suggests that cottage cheese consumers are interested in a fat/calorie reduction, as cottage cheese is commonly imaged as a diet product; however, flavor is still important such that a fat-free product was not attractive.

Product price is also known to be a driver of choice; therefore, it was also expected that price would have a large effect on importance scores and that a low price is more attractive than a higher price, as was observed in this study (Jervis et al., 2012a; Kim et al., 2013). Cottage cheese brand had a lower effect on importance scores for most consumers, perhaps because cottage cheese brands are not well known or well differentiated from store brand products (Dairy Foods, 2006). From conjoint analysis, the most appealing cottage cheese to all consumers was an established, recognized brand, all-natural label claim, reduced fat ( $2 \%$ milkfat), and a 16 -ounce container with a low price.

Consumers were segmented into 3 distinct clusters based on utility scores (Figure 2, Table 3). Consumers were mostly female (84\%), evenly distributed among ages 25 to 64 yr old, and $>70 \%$ had 2 to 4 household 
members. Seventy-nine percent were Caucasian, and $13 \%$ were African American. More than $60 \%$ described their eating habits as healthy or moderately healthy. No differences were observed in these attributes among the 3 identified consumer clusters $(P>0.05)$. Cluster analysis revealed that fat content was the driver of choice for clusters 2 and 3, whereas price was the primary driver of choice for cluster 1 (Figure 1). Clusters 2 and 3 were further differentiated based on brand. Cluster 3 consumers were more brand conscious. Based on responses, cluster $1(\mathrm{n}=149)$ consumers can be described as price conscious. Price was the primary driver of choice for this cluster, followed by fat content $(P<$ 0.05 ). Other cluster 1 attributes, brand, label claim, and package size, received lower importance scores and were at parity with each other $(P>0.05$; Figure 1$)$. Cluster 1 preferred $\$ 1.75$ for price (Table 3), closely followed by $\$ 2.00$ and $\$ 2.25$. The lowest price $(\$ 1.50)$ was likely not preferred because reduced cost is often associated with reduced quality and $\$ 1.75$ appears to be the threshold for that perception with this cluster. Within fat content, cluster 1 consumers strongly preferred reduced $2 \%$ milkfat. A 16-ounce package was preferred for package size, and was at parity with the 24-ounce package size, followed by 4 ounces (snack size). Digestive benefits, excellent source of calcium, all natural, and regular (no claim) received the highest utility scores within the attribute label claims, and were at parity with each other $(P>0.05)$. Within the brand attribute, cluster 1 utility scores were highest for the well-established and recognized brand Breakstone, closely followed by Daisy Brand.

For cluster $2(\mathrm{n}=183)$ consumers, fat content was the primary driver of choice followed by price and brand, respectively. Within the fat content attribute, the low/light/lite $1 \%$ milkfat level received the highest utility scores for cluster 2 consumers (Table $3 ; P$ $<0.05)$. The price $\$ 1.75$ was most preferred among price attributes, closely followed by $\$ 2.00$ and $\$ 2.25$ at parity $(P>0.05)$. Similarly to cluster 1 , the lowest price, $\$ 1.50$ was likely not preferred because of a negative association between low cost and poor quality. Among brands, Breakstone was most preferred. Daisy Brand and the organic brand (Organic Valley) received slightly lower scores for brand and were at parity $(P>$ 0.05). Out of label claims, cluster 2 consumers strongly preferred excellent source of calcium compared with other label claims $(P<0.05)$. Within the package size attribute, 16 ounces was strongly preferred by cluster 2 consumers $(P<0.05)$. Scores for cluster 2 were very similar to cluster 3 scores; however, cluster 2 consumers were more price conscious and less brand aware.

Fat content received the highest importance score within cluster 3 , followed by brand. The attributes

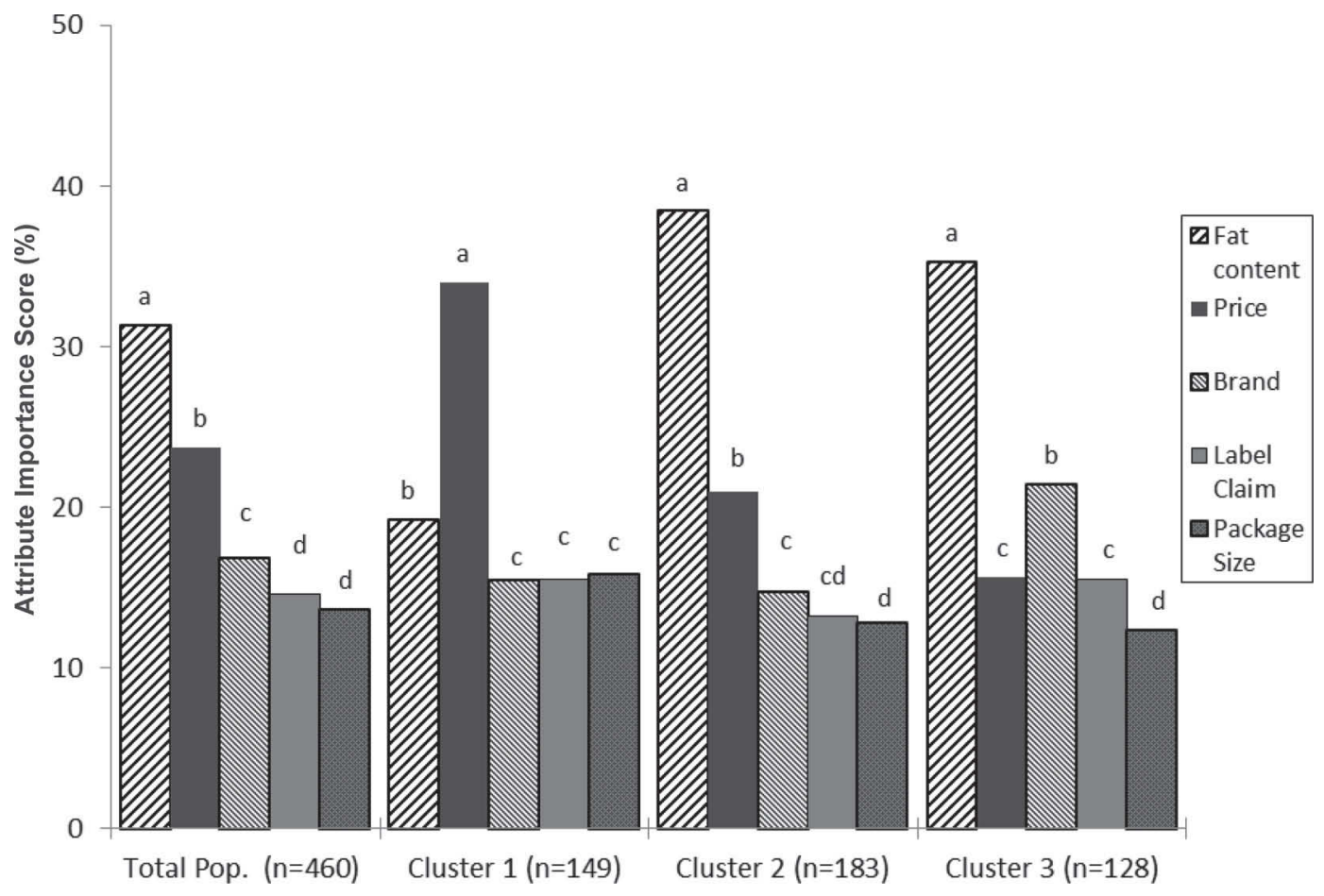

Figure 1. Attribute importance (\%) scores for the total population (pop.) and segmented groups. Letters (a-d) indicate significant differences $(P<0.05)$ within total population $(\mathrm{n}=460)$, or within each cluster [cluster $1(\mathrm{n}=149)$, cluster $2(\mathrm{n}=183)$, and cluster $3(\mathrm{n}=128)$ ]. 
price and label claim received importance scores below brand scores and were at parity $(P>0.05)$. Label claim and package size received the lowest attribute importance scores and were at parity $(P>0.05)$. Like the other clusters, within the brand attribute, Breakstone received the highest utility score followed by Daisy Brand. Within label claim, all natural, regular (no claim), and excellent source of calcium were most preferred and were at parity $(P<0.05)$. Within the package size attribute, 16 ounces was preferred by cluster 3 consumers $(P<0.05)$ followed by 24 and 4 ounces, respectively.

\section{Kano Analysis}

Conjoint analysis is used to assess and determine drivers of product choice, Kano questions are used to understand the underlying factors affecting satisfaction or dissatisfaction related to a product (Xu et al., 2008; Kim et al., 2013). The Kano model assigns consumer product features into 4 categories: must-have attributes are those taken for granted when met, but lead to high dissatisfaction when not met. One-dimensional attributes contribute to a linear increase in customer satisfaction as the presence of the attribute increases. Attractive attributes are unexpected and can increased consumer satisfaction if available; however, they do not have an adverse effect on satisfaction if absent. Indifferent attributes do not have a significant positive or negative effect on liking (Xu et al., 2008).

Attractive attributes were generally consistent between conjoint and Kano results. Reduced fat was an attractive attribute (Table 4), consistent with conjoint results. The low utility scores for the lactose-free brand, Lactaid, and for the label claim organic were also confirmed by indifferent Kano results for lactose free and organic across all clusters (Table 4). Digestive benefits, all natural, and reduced fat were drivers of choice by conjoint analysis, and Kano results confirmed that these attributes were unexpected (attractive) for the population. Kano results indicated that both flavor and healthy attributes were primary drivers of product

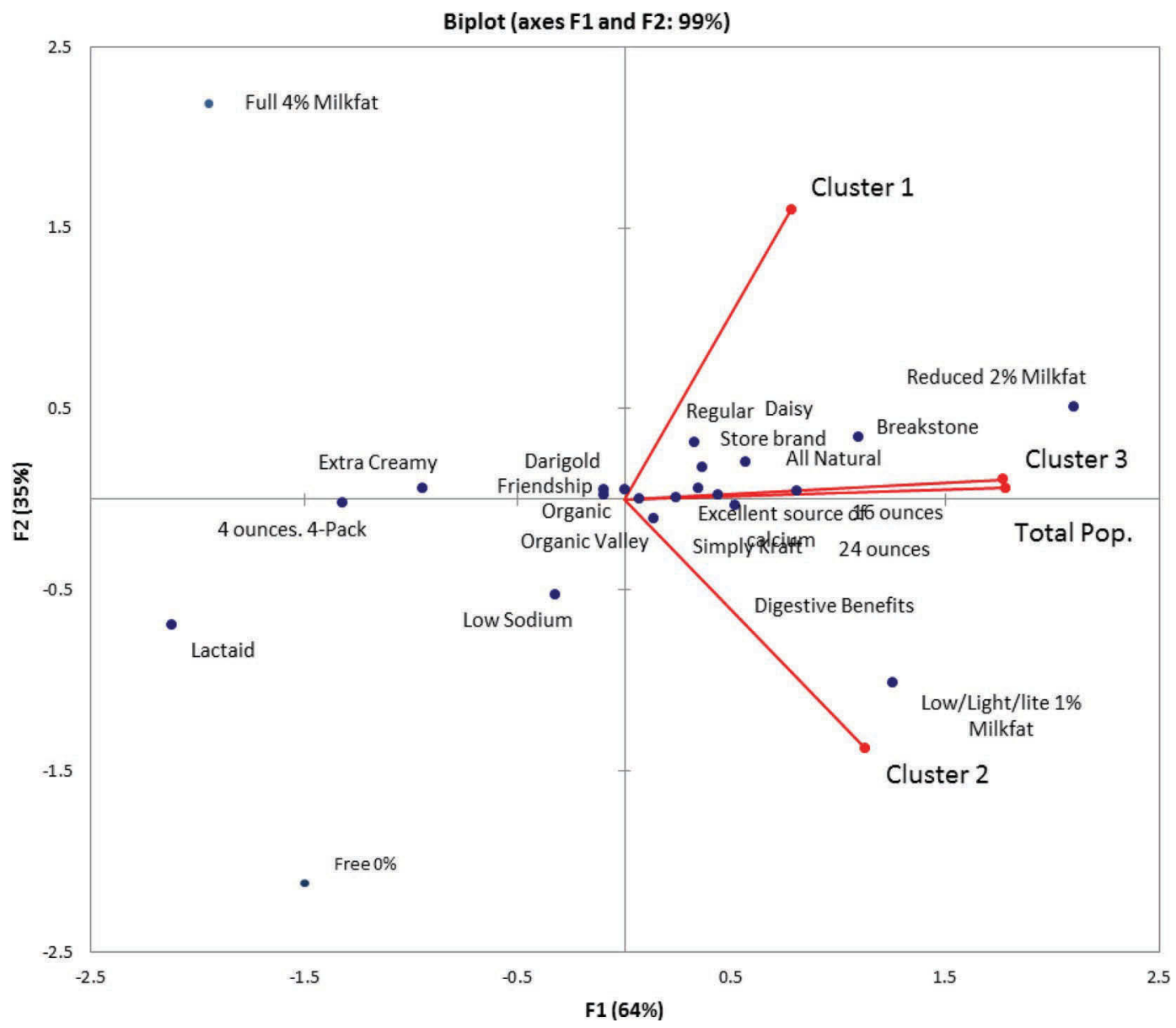

Figure 2. Principal component biplot of utilities and attributes within clusters. Pop. = population. Color version available online. 
Table 4. Kano feature scores for total population and individual clusters

\begin{tabular}{|c|c|c|c|c|}
\hline Feature & \multicolumn{4}{|c|}{ Kano classification } \\
\hline Keeps me full for a long time & Attractive & Attractive & Attractive & Attractive \\
\hline Low sodium & Indifferent & Indifferent & Indifferent & Indifferent \\
\hline Digestive benefits & Attractive & Attractive & Attractive & Indifferent* \\
\hline All natural & Attractive & Attractive & Indifferent* & Indifferent* \\
\hline Organic & Indifferent & Indifferent & Indifferent & Indifferent \\
\hline Full fat & Indifferent & Indifferent & Indifferent & Indifferent \\
\hline Creamy & Must have & Must have & Must have & Must have \\
\hline Reduced fat & Attractive & Attractive & Attractive & Indifferent* \\
\hline Fat free & Indifferent & Indifferent & Indifferent & Indifferent \\
\hline
\end{tabular}

*Results that are different from the total population.

satisfaction. A similar study using conjoint and Kano analysis showed that fat and sugar were the primary drivers of product choice and satisfaction for chocolate milk (Kim et al., 2013). Kano and conjoint results indicated drivers of purchase intent and satisfaction; however, if expectations are not fulfilled during sensory evaluation, the product overall liking will be reduced.

\section{Consumer Acceptance of Cottage Cheese}

Expected Condition. Consumer testing of expected condition tests the perceived quality of the brand (Shepherd et al., 1991/1992; Kim et al., 2013). Knowledge of only brand (expected condition) affected overall liking $(P<0.05$; Table 5). One national brand and one store brand received the highest scores (Table 5, Figure 3). Previous studies on the influence of brand on expected liking have shown similar results. In the presence of brand, liking scores for some products are significantly increased due to the branding effect (Guinard et al., 2001), so differences in liking of brand alone (expected liking) would also be expected. Liking differences among brands alone suggest that even through brand was not a primary driver of choice for cottage cheese by conjoint analysis, it still has an influence on consumers. Blind tasting might not always appropriately predict consumers liking of a product. Consumer expected liking scores are shown in an internal preference map to provide clarity (Figure 3). In these maps, consumer liking scores are indicated by the dots with the products overlaid. Products that are associated with a high density of dots (consumer liking scores) are products that are liked. In the case on expected liking, one store brand (store brand 2) and one national brand (national brand 1) received the highest expected liking scores. Interestingly, the organic brand received a low expected liking score, indicating that an organic brand may be attractive to only a small cluster of consumers, or possibly a driver of dislike if associated with off-flavors or unfamiliar tastes. It is important to note that this was a specific organic brand tested rather than an organic label attribute, and with only 1 organic brand evaluated we cannot make sweeping conclusions about an organic label, although the conjoint and Kano survey results also suggest that organic is not an important attribute for cottage cheese.

Blind Condition. Blind conditions are what is typically done with traditional hedonic tasting and determines consumer liking and perception of product sensory attributes. Overall liking scores ranged from 5.1 to 6.3 on a 9 -point hedonic scale under blind conditions $(P<0.05$, Table 5$)$. Also, distinct differences

Table 5. Overall liking scores of cottage cheeses evaluated under blind, expected, and informed conditions by consumers $(\mathrm{n}=150)^{1}$

\begin{tabular}{lccc}
\hline & \multicolumn{2}{c}{ Evaluated condition } & \\
\cline { 2 - 3 } Brand $^{2}$ & Informed & Blind & Expected \\
\hline NB1 & $6.6^{\mathrm{a}, \mathrm{A}}$ & $6.4^{\mathrm{a}, \mathrm{A}}$ & $5.8^{\mathrm{ab}, \mathrm{B}}$ \\
NB2 & $6.2^{\mathrm{b}, \mathrm{A}}$ & $6.1^{\mathrm{ab}, \mathrm{A}}$ & $4.9^{\mathrm{c}, \mathrm{B}}$ \\
RB1 & $6.4^{\mathrm{ab}, \mathrm{A}}$ & $5.9^{\mathrm{b}, \mathrm{B}}$ & $5.1^{\mathrm{bc}, \mathrm{C}}$ \\
RB2 & $5.7^{\mathrm{cd}, \mathrm{A}}$ & $5.7^{\mathrm{bc}, \mathrm{A}}$ & $5.3^{\mathrm{b}, \mathrm{B}}$ \\
SB1 & $5.3^{\mathrm{d}, \mathrm{B}}$ & $5.3^{\mathrm{d}, \mathrm{B}}$ & $5.7^{\mathrm{b}, \mathrm{A}}$ \\
SB2 & $5.9^{\mathrm{bc}, \mathrm{B}}$ & $5.5^{\mathrm{c}, \mathrm{C}}$ & $6.3^{\mathrm{a}, \mathrm{A}}$ \\
OB & $6.2^{\mathrm{b}, \mathrm{A}}$ & $5.2^{\mathrm{d}, \mathrm{B}}$ & $5.1^{\mathrm{bc}, \mathrm{B}}$ \\
\hline
\end{tabular}

${ }^{\mathrm{a}-\mathrm{d}}$ Different lowercase letters in columns following means indicate significant differences $(P<0.05)$.

${ }^{\mathrm{A}-\mathrm{C}}$ Different uppercase letters in rows following means indicate significant differences $(P<0.05)$.

${ }^{1}$ Liking attributes were scored on a 9 -point hedonic scale, where dislike extremely $=1$ and like extremely $=9$.

${ }^{2} \mathrm{NB}=$ national brand, $\mathrm{RB}=$ regional brand, $\mathrm{SB}=$ store brand, $\mathrm{OB}$ $=$ organic brand. 
were observed in appearance liking and color liking for each cottage cheese $(P<0.05$; results not shown). Cottage cheese appearance was negatively affected $(P<$ $0.05)$ by "much too small" curd size, and "much too large" curd. In addition, appearance was negatively affected $(P<0.05)$ by the presence of too little or too much dressing. Drake et al. (2009) also confirmed the role of curd size and dressing-to-curd ratio on consumer acceptance of cottage cheese.

A condition $\times$ treatment interaction was present for tasting in the presence or absence of the brand (blind vs. informed; $P<0.05$ ). Under the blind condition, national brands 1 and 2 received the highest scores but these scores were lower $(P<0.05)$ than scores received by the same treatments under the informed condition (Table 5), although both products were consistently liked by consumers relative to other products (Figures 3 , 4, and 5). Just-about-right scores suggested that reduced liking scores for all products were due to soft curd texture and low saltiness, also established as negative consumer attributes for cottage cheese (Drake et al., 2009).

Informed Condition. Informed tasting evaluates the consumer liking of perception of product sensory attributes with product branding present. Under the informed condition, overall liking scores ranged from

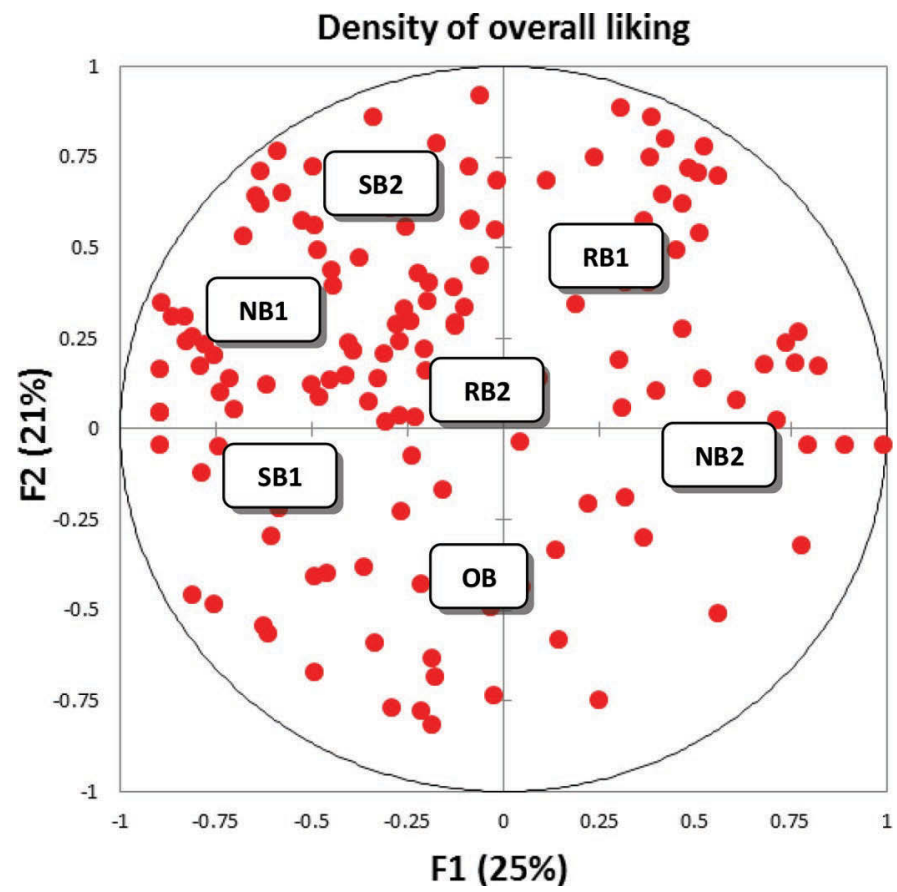

Figure 3. Internal preference map of consumers liking scores of cottage cheeses evaluated under Expected condition (brand only). Data points indicate overall liking. $\mathrm{NB}=$ national brand, $\mathrm{RB}=$ regional brand, $\mathrm{OB}=$ organic brand, and $\mathrm{SB}=$ store brand. Color version available online.

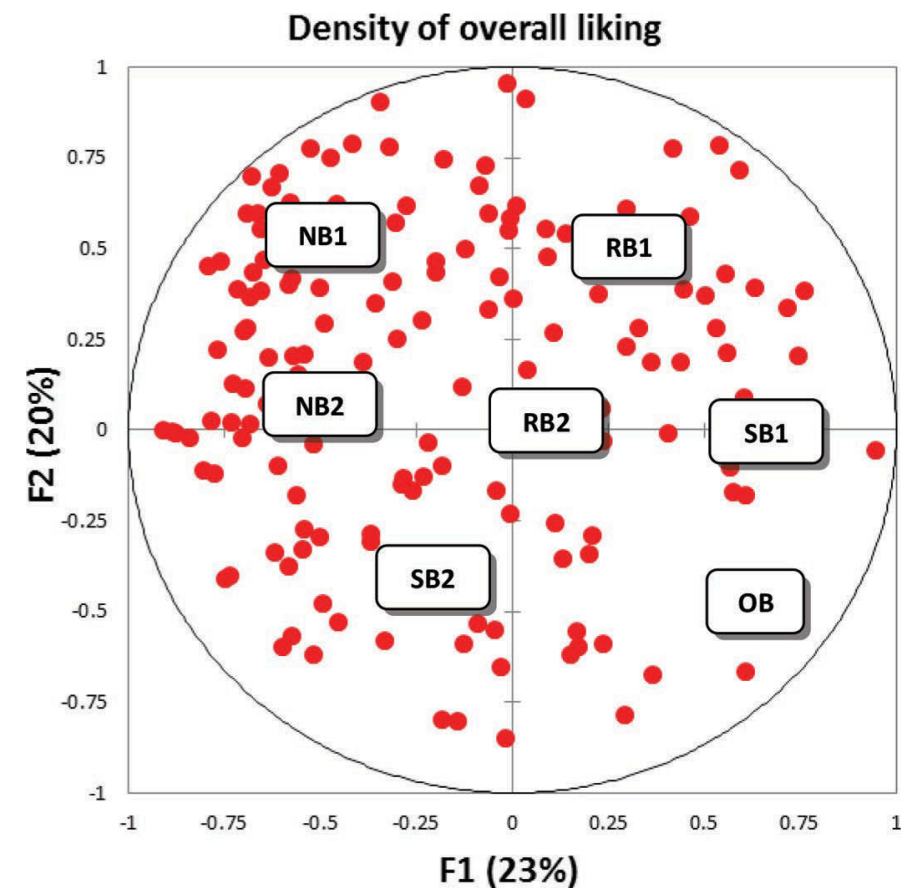

Figure 4. Internal preference map of consumers liking scores of cottage cheeses evaluated under the blind condition. Data points indicate overall liking. $\mathrm{NB}=$ national brand, $\mathrm{RB}=$ regional brand, $\mathrm{OB}=$ organic brand, and $\mathrm{SB}=$ store brand. Color version available online.

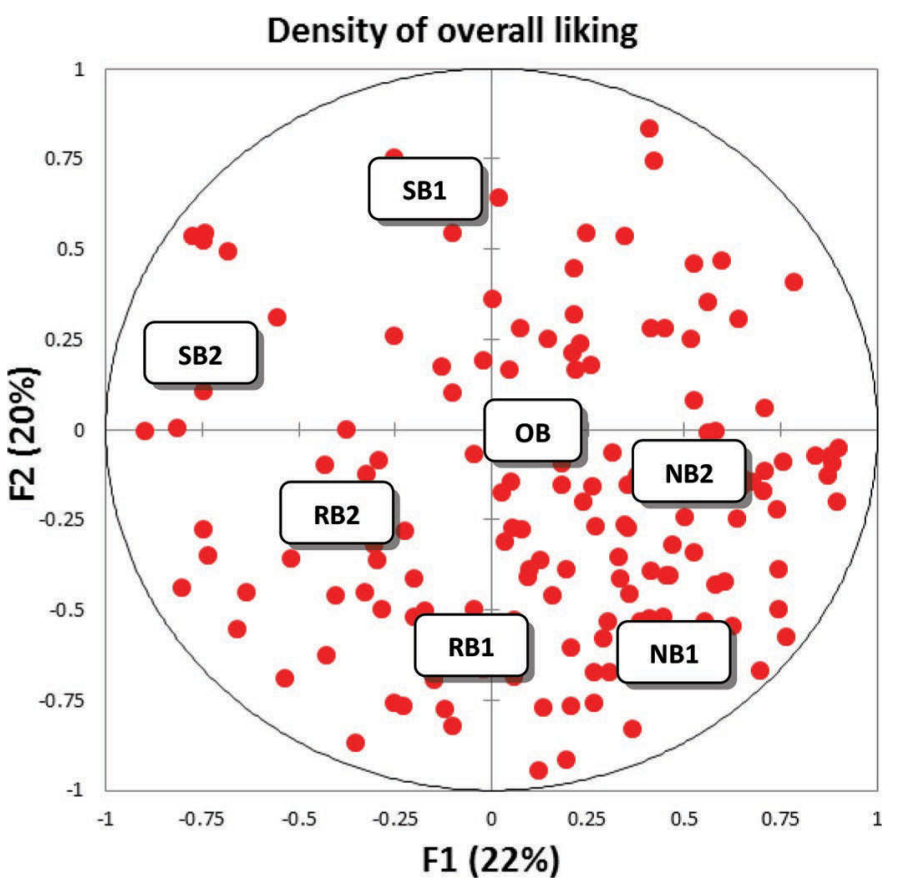

Figure 5. Internal preference map of consumers liking scores of cottage cheeses evaluated under Informed condition. Data points indicate overall liking. $\mathrm{NB}=$ national brand, $\mathrm{RB}=$ regional brand, $\mathrm{OB}=$ organic brand, and $\mathrm{SB}=$ store brand. Color version available online. 
5.3 to 6.6 and were distinct among products $(P<0.05$, Table 5). Informed condition overall liking scores were generally higher than blind conditions although this effect was variable with brand. Overall liking scores under informed conditions were clustered around national and regional brands (Figure 5). Liking of national, regional, and organic brands under informed conditions were elevated compared with expected liking. Liking scores of the 2 store brands were decreased compared with the expected liking. Liking scores of other products under informed conditions were higher or unchanged compared with blind tasting. The organic brand product had the highest increase in liking when tasted in the presence of the brand. When compared with the decreased expected and blind liking scores, this suggests that the organic brand may have had a negative effect on consumer perception and that the product itself was not well liked. However, when the product was tasted with knowledge that the product was also organic, a halo effect was found. Perhaps consumer expectations for organic cottage cheeses are low and this product exceeded previous expectations.

Similar studies have shown variable results with tasting in the presence versus absence of brand, demonstrating that brand has a variable effect. In a study with yogurt products, Bayarri et al. (2011) found that nutritional and product information did not have an influence on product acceptability. Torres-Moreno et al. (2012) evaluated the influence of label information on dark chocolate acceptability showed that higher expectations were generated by premium brands compared with store brands. When tasted with branding present, name brand products received higher scores than store brand products; however, when tasted without brand present store brand products were found to be as acceptable as name brand products. Kim et al. (2013) evaluated label attributes of chocolate milk and demonstrated that brand had an effect on product liking but that consumers prioritized other product attributes, such as fat or sugar content, over brand (Kim et al., 2013). This suggests that a variety of factors including sensory characteristics (extrinsic and intrinsic) and consumer preferences play a role in cottage cheese acceptance.

\section{CONCLUSIONS}

Due to its traditional presence in the dairy case, we expected that cottage cheese brands would have a low to moderate effect on the overall liking of cottage cheese products. Results from this study confirm that fat content and price have a greater effect on cottage cheese selection, but brand is also a driver of product choice. Cottage cheeses generally had increased liking in the presence of national, regional, and organic brands when tasted compared with expected liking, but this effect was not noted for store brands. Store brand products may not deliver expected sensory attributes compared with their name brand counterparts. Name brand manufacturers should leverage brand (advertising). Store brand manufacturers should create a product image that communicates name brand quality and delivers expected intrinsic (flavor and texture) attributes. Label claim and package size are not consumer priorities for cottage cheese; however, levels within these attributes such as the "all natural" label claim, and 16-ounce package size can be used to increase consumer product acceptance. Meeting consumer needs and desires (healthy/tastes good) could significantly increase product demand for cottage cheese.

\section{ACKNOWLEDGMENTS}

Funding was provided in part by the National Dairy Council (Rosemont, IL). The use of trade names does not imply endorsement of these brands nor lack of endorsement of those not mentioned.

\section{REFERENCES}

Andreyeva, T., M. W. Long, and K. D. Brownell. 2010. The impact of food prices on consumption: A systematic review of research the price elasticity of demand for food. Am. J. Public Health 100:216-222.

Antinone, M. J., H. T. Lawless, R. A. Ledford, and M. Johnston. 1994. Diacetyl as a flavor component in full fat cottage cheese. J. Food Sci. 59:38-42.

Bayarri, S., I. Carbonell, E. X. Barrios, and E. Costell. 2011. Impact of sensory differences on consumer acceptability of yoghurt and yoghurt-like products. Int. Dairy J. 21:111-118.

Bodyfelt, F. W., and D. Potter. 2009. Sensory evaluation of creamed cottage cheese. Pages 167-190 in The Sensory Evaluation of Dairy Products. S. Clark, M. Costello, M. A. Drake, and F. Bodyfelt, ed. Van Nostrand Reinhold, New York, NY.

Chen, L. 2012. A novel approach to regression analysis for the classification of quality attributes in the Kano model: An empirical test in the food and beverage industry. Omega 40:651-659.

Childs, J. L., J. L. Thompson, J. S. Lillard, T. K. Berry, and M. A. Drake. 2008. Consumer perception of whey and soy protein in meal replacement products. J. Sens. Stud. 23:320-339.

Code of Federal Regulations. 2004. Code of Federal Regulations, title 21. Vol. 2: Food and drugs. U.S. Government Printing Office. Accessed Apr. 1, 2015. http://www.accessdata.fda.gov/scripts/cdrh/ cfdocs/cfcfr/CFRSearch.cfm?fr $=133.128$.

Cunningham, C. E., K. Deal, and Y. Chen. 2010. Adaptive choicebased conjoint analysis. Patient 3:257-273.

Dairy Foods. 2006. Lowfat milk sales slumping, cottage cheese brands grow. Accessed Aug. 22, 2014. http://www.dairyfoods.com/ articles/dairy-market-trends-lowfat-milk-sales-slumping-cottagecheese-brands-grow? $\mathrm{v}=$ preview.

Dairy Market Trends. 2005. Yogurt sales pace quickens, cottage cheese shrinks. Accessed Feb. 17, 2014. http://www.dairyfoods.com/ articles /82608-dairy-market-trends-yogurt-sales-pace-quickenscottage-cheese-shrinks.

Davis, C. G., D. P. Blayney, D. Dong, S. Stefanova, and A. Johnson. 2010. Long term growth in U.S. cheese consumption may slow. USDA Economic Research Service, LDP-M-193-01. 
Drake, S. L., K. Lopetcharat, and M. A. Drake. 2009. Comparison of two methods to explore consumer preferences for cottage cheese. J. Dairy Sci. 92:5883-5897.

Gelici-Zeko, M. M., D. Lutters, R. ten Klooster, and P. L. G. Weijzen. 2012. Studying the influence of packaging design on consumer perceptions (of dairy products) using categorizing and perceptual mapping. Pack. Tech. Sci. 26:215-228.

Gensler, S., O. Hinz, B. Skiera, and S. Theysohn. 2012. Willingnessto-pay estimation with choice-based conjoint analysis: Addressing extreme response behavior with individually adapted designs. Eur. J. Oper. Res. 219:368-378.

Guinard, J. X., U. Bunsaku, and P. Schlich. 2001. Internal and external mapping of preferences for commercial lager beers. Comparison of hedonic ratings by consumers blind versus with knowledge of brand and price. Food Qual. Prefer. 12:243-255.

Hoyer, W. D., and S. P. Brown. 1990. Effects of brand awareness on choice for a common, repeat-purchase product. J. Consum. Res. 17:141-148.

Jervis, S. M., J. M. Ennis, and M. A. Drake. 2012a. A comparison of choice based conjoint versus adaptive choice based conjoint in the evaluation of drivers of choice of sour cream with limited sample size. J. Sens. Stud. 27:451-462.

Jervis, S. M., K. Lopetcharat, and M. A. Drake. 2012b. Application of ethnography and conjoint analysis to determine key consumer attributes for latte-style coffee beverages. J. Sens. Stud. 27:48-58.

Kim, M. K., K. Lopetcharat, and M. A. Drake. 2013. Influence of packaging information on consumer liking of chocolate milk. J. Dairy Sci. 96:4843-4856.

Kuo, C. M., S. H. You, and C. Y. Lu. 2014. Integration of the Kano and QFD model in health food development: Using black beans as examples. Qual. Quant. 48:225-242.

MacFie, H. J., N. Bratchell, K. Greenhoff, and L. V. Vallis. 1989. Designs to balance the effect of order of presentation and first-order carry-over effects in hall tests. J. Sens. Stud. 4:129-148.

Mahanna, K., H. R. Moskowits, and S. Y. Lee. 2009. Assessing consumer expectations for food bars by conjoint analysis. J. Sens. Stud. 24:851-870.

Makhal, S., S. K. Kanawjia, and A. Giri. 2013. A dual-acidification process for the manufacture of direct-acidified cottage cheese. Int. J. Dairy Technol. 66:552-561.

Maniar, A. B., J. E. Marcy, J. R. Bishop, and S. E. Duncan. 1994 Modified atmosphere packaging to maintain direct-set cottage cheese quality. J. Food Sci. 59:1305-1308.

Mesías, F. J., F. Martinez-Carrasco, J. M. Martinez, and P. Gaspar. 2011. Functional and organic eggs as an alternative to conventional production: A conjoint analysis of consumers' preferences. J. Sci. Food Agric. 91:532-538.

Monsoor, M. A., K. Farooq, and Z. U. Haque. 2003. Cottage cheese whey as an ingredient of cottage cheese dressing mixes. Int. J. Dairy Technol. 56:17-21.
Moskowitz, H. R., J. H. Beckley, and A. V. A. Resurreccion. 2006. High-level product assessment. Pages 167-205 in Sensory and Consumer Research in Food Product Development. Blackwell Publishing, Ames, IA.

Onozaka, Y., and D. T. McFadden. 2011. Does local labelling complement or compete with other sustainable labels? A conjoint analysis of direct and joint values for fresh produce claims. Am. J. Agric. Econ. 93:693-706.

Orme, B. K. 2010. Getting Started with Conjoint Analysis: Strategies for Product Design and Pricing Research. Research Publishers, Madison, WI.

Paasovaara, R., H. T. Luomala, T. Pohjanheimo, and M. Sandell. 2012. Understanding consumers' brand-induced food taste perception: A comparison of 'brand familiarity' - and 'consumer valuebrand symbolism (in) congruity'-accounts. J. Consum. Behav. 11:11-20

Priilaid, D. A. 2006. Wine's placebo effect: How the extrinsic cues of visual assessments mask the intrinsic quality of South African red wine. Int. J. Wine Mark. 18:17-32.

Puspitasari, N. L. K. Lee, and J. L. Greger. 1991. Calcium fortification of cottage cheese with hydrocolloid control of bitter flavor defects. J. Dairy Sci. 74:1-7.

Reiter, J. 1993. Saving a category (Cottage cheese). Accessed Dec. 18, 2008. http://highbeam.com/doc/1G1-14080734.html.

Richardson-Harman, N. J., R. Stevens, S. Walker, J. Gamble, M. Miller, M. Wong, and A. McPherson. 2000. Mapping consumer perceptions of creaminess and liking for liquid dairy products. Food Qual. Prefer. 11:239-246.

Shepherd, R., P. Sparks, S. Belier, and M. M. Raats. 1991/1992. The effect of information on sensory ratings and preferences: The importance of attitudes. Food Qual. Prefer. 3:147-155.

Tong, P. 2013. You don't know beans about cottage cheese. Dairy Foods. December, p. 26

Torres-Moreno, M., A. Tarrega, E. Torrescasana, and C. Blanch. 2012. Influence of label information on dark chocolate acceptability. Appetite 58:665-671.

USDA National Agricultural Statistics Service. 2007. Dairy Products 2006 Summary. Accessed Oct. 15, 2013. http://usda.mannlib. cornell.edu/MannUsda/viewDocumentInfo.do?documentID =1054

Varela, P., A. Gaston, A. Giminez, and A. Gambaro. 2010. Influence of brand information on consumers' expectations and liking of powdered drinks in central location tests. Food Qual. Prefer. $21: 873-880$.

Xu, Q., R. J. Jiao, X. Yang, and M. Helander. 2008. An analytical Kano model for customer needs analysis. Des. Stud. 30:87-110. 